\title{
EPIDERMÓIDE INTRA-RAQUEANO
}

\author{
ANTONIO B. LEFÈVRE * \\ Rolando A. Tenuto **
}

Amelia T. M. Vasconcelos ***

A oportunidade que tivemos de observar um caso de epidérmoide intra-raqueano levou-nos a êste registro, tendo em vista a raridade da incidência dêste tipo de tumor em crianças. Julgamos também ser de interêsse chamar a atenção para a confusão da nomenclatura anátomo-patológica que torna extremamente difícil um levantamento do total dos casos registrados na literatura. Por estranho que pareça, em compêndio recentíssimo como o de Ingraham e Matson ", contendo um cepitulo onde são estudados os "Congenital Dermal Sinus Tracts" (pág. 69) e outro em que são estudados os tumores intraespinais (pág. 345), pràticamente não é dada importância à distinção entre os dermóides e os epidermóides; no estudo analítico dos 63 casos de tumores intra-raqueanos há referência a 9 "cistos dermóides" sem qualquer elemento para assegurar que os autores tenham tentado distinguir êstes tumores dos epidermóides.

OBSERvaÇÃo - G. D. C., 9 anos, sexo masculino, branco, italiano, internado em 7-6-1956 (R. G. 442.321). Antecedentes pessoais e familiares sem interésse para o caso. História da moléstia atual — Há um ano, realizando uma ginástica que consistia em prender as pernas "em tesoura" na cintura do pai e jogar o corpo para trás, apresentou dôres de pequena duração no membro inferior esquerdo ao nível do terço médio anterior da coxa; um mês após apresentou dor na região lombar. Essas dores reapareciam tôda vez que o paciente "dava um mau geito no corpo". Dois a três meses depois do início começou a notar parestesias ao longo da pantorrilha esquerda. Em 30-5-1956 procurou o ambulatório da Clínica Neurológica onde, com a suspeita de hérnia discal ou tumor intra-raquiano, foi pedido exame de liquor. Após a punção lombar passou a apresentar dor ao longo da face ântero-lateral da perna direita. O exame de liquor mostrou: pressão inicial $16 \mathrm{~cm}$ de água; provas manométricas de Stookey mostrando estar parcialmente bloqueado o canal raquiano; liquor límpido e incolor; 0 células por $\mathrm{mm}^{3} ; 40 \mathrm{mg}$ de proteina total por $100 \mathrm{ml}$; reaçōes de Pandy e Nonne (positivas ( +); reação de Takata-Ara positiva $(+)$ tipo misto; reação do benjoim 00001.22222.21000.0; rea çōes para lues negativas; reação de Weinberg (cisticercose) positiva ++ com $1 \mathrm{ml}$. Em vista dêste exame o paciente foi internado com suspeita de bloqueio raquidiano por granuloma cisticercótico. Exame físico - Escoliose da coluna vertebral com convexidade para a direita e contratura da musculatura paravertebral esquerda, principalmente ao nivel da região lombar. Nenhuma alteração da pele na região lombar (mancha, retração, umbelicação, pêlos). Em decúbito dorsal, impos-

Trabalho da Clinica Neurológica da Fac. Med. Univ. de São Paulo (Prof. Adherbal Tolosa): * Livre-Docente; ** Neurocirurgião chefe; *** Estagiária. 
sibilidade de sentar-se mantendo os membros inferiores em extensão. Pelas manobras de Barré e Mingazzini, cansaço no membro inferior esquerdo. Sinal de Lasègue presente. Em bipedestação, uma pressão brusca sôbre a cabeça determinava aparecimento de dor na regiāo lombar. Pela inclinaçāo do corpo para frente aparecia dor na região lombar, o mesmo acontecendo pela flexão lateral do corpo para a direita. Manobra de Nafftziger positiva. Reflexos: aquileos abolidos; cremasterino só obtido à direita; os demais normais. Sensibilidade aparentemente conservada, a não ser certa dificuldade em reconhecer o frio ao nivel dos maleólos internos. Perfeito contrôle de esfincteres.

Com éste exame neurológico e em face do resultado da punção lombar, foi levantada a suspeita de um granuloma cisticercótico intra-raquiano, hipótese esta aparentemente confirmada pela positiviàade da reação de Weinberg no sôro sanguineo aliada a reações sorológicas para lues negativas.

A perimielografia mostrou bloqueio completo e duradouro do contraste em $T_{12}$; o limite superior do bloqueio era irregular e concavo para baixo. Como persistissem dúvidas quanto à etiologia foi repetido o exame de líquor (13-6-1956) que confirmou a hipótese de granuloma cisticercótico: punção ao nivel do espaço $\mathrm{L}_{3}-\mathrm{L}_{4}$, paciente em decúbito lateral; pressão inicial $10 \mathrm{~cm}$ de água; pressão negativa após a retirada de $2 \mathrm{ml}$ de líquor; líquor límpido e incolor; 0,8 células por $\mathrm{mm}^{3} ; 280 \mathrm{mg}$ de proteinas totais por $100 \mathrm{ml}$; reação de Pandy positiva ++ ; reação de Weinberg (cisticercose) positiva $++\operatorname{com} 0,5 \mathrm{ml}$.

Operação cirúrgica - Laminectomia tóraco-lombar em 20-6-1956: excisão das apófises espinhosas e lâminas de $T_{12}$ até $L_{2}$; espaso epidural e dura-mater sem alterações macroscópicas; pela palpação através da dura-mater, tumor de consistência dura ao nivel de $\mathrm{T}_{12}$; abertura das membranas com visualização mediata, sob a aracnóide, de um tumor extra-medular de coloração perlácea, encapsulado, que comprimia o cone medular e se insinuava entre as raizes da cauda equina; libertaçāo das aderências e extirpação em bloco do tumor.

Diagnóstico anátomo-patológico - Peça de forma ovóide, medindo cêrca de 4 $\mathrm{cm}$ no maior eixo. Superfície externa lisa, mostrando por transparência finos vasos de trajeto retilineo. Ao corte, peça constituida por um cisto de paredes finas, com espessura média de 1 a $2 \mathrm{~mm}$, contendo material pastoso, branco-amarelado, com aspecto de sebo. Superficie interna lisa e brilhante, constituida por tecido epitelial planocelular corneificado, sem sinais de malignidade. $\mathrm{Em}$ correspondência à superficie externa do cisto, nota-se a presença de tecido conjuntivo frouxo, infiltrado por escassa quantidade de linfócitos. Não se nota a presença de glândulas sudoriparas ou sebáceas, nem de folículos pilosos. Diagnóstico: Cisto epidermóide (Dr. L. C. Mattosinho França).

Evolução sem incidentes com boa recuperação funcional. Um exame de liquor no periodo pós-operatório mostrou: punção lombar entre $\mathrm{L}_{5}-\mathrm{S}_{1}$; pressão inicial 14 $\mathrm{cm}$ de água; Stookey normal; liquor limpido e incolor; $50 \mathrm{mg}$ de proteinas totais por $100 \mathrm{ml}$; reação de Pandy positiva +; reação de benjoim 01101.22221.00000.0; reação de Takata-Ara positiva + (tipo floculante). Para comparação foi feita também punção suboccipital: pressão inicial $5 \mathrm{~cm}$ de água; líquor límpido e incolor; 3 células por $\mathrm{mm}^{3} ; 30 \mathrm{mg}$ de proteinas totais por $100 \mathrm{ml}$; reação de Pandy positiva + ; reação de benjoim 00000.12210.00000.0. Estes exames mostraram desaparecimento do bloqueio raquidiano, embora persistisse relativamente elevada a taxa de proteinas em punção lombar. Fato interessante verificado neste exame foi a negatividade da reação de Weinberg (cisticercose). Poderiamos supor que nos exames feitos anteriormente à operação a positividade dessa reação corresse por conta de uma hiperproteinorraquia (respectivamente $40 \mathrm{mg}$ e $280 \mathrm{mg}$ por $100 \mathrm{ml}$ ) sendo, portanto, uma positividade falsa, embora a positividade da reação no sôro sanguíneo falasse a favor de um resultado real. Entretanto, esta tentativa de explicar a positividade da reação de Weinberg pela hiperproteinorraquia não deve subsistir, uma vez que no exame pós-operatório a taxa de proteinas estava também elevada (50 $\mathrm{mg}$ por $100 \mathrm{ml}$ ) sendo essa reação negativa. 

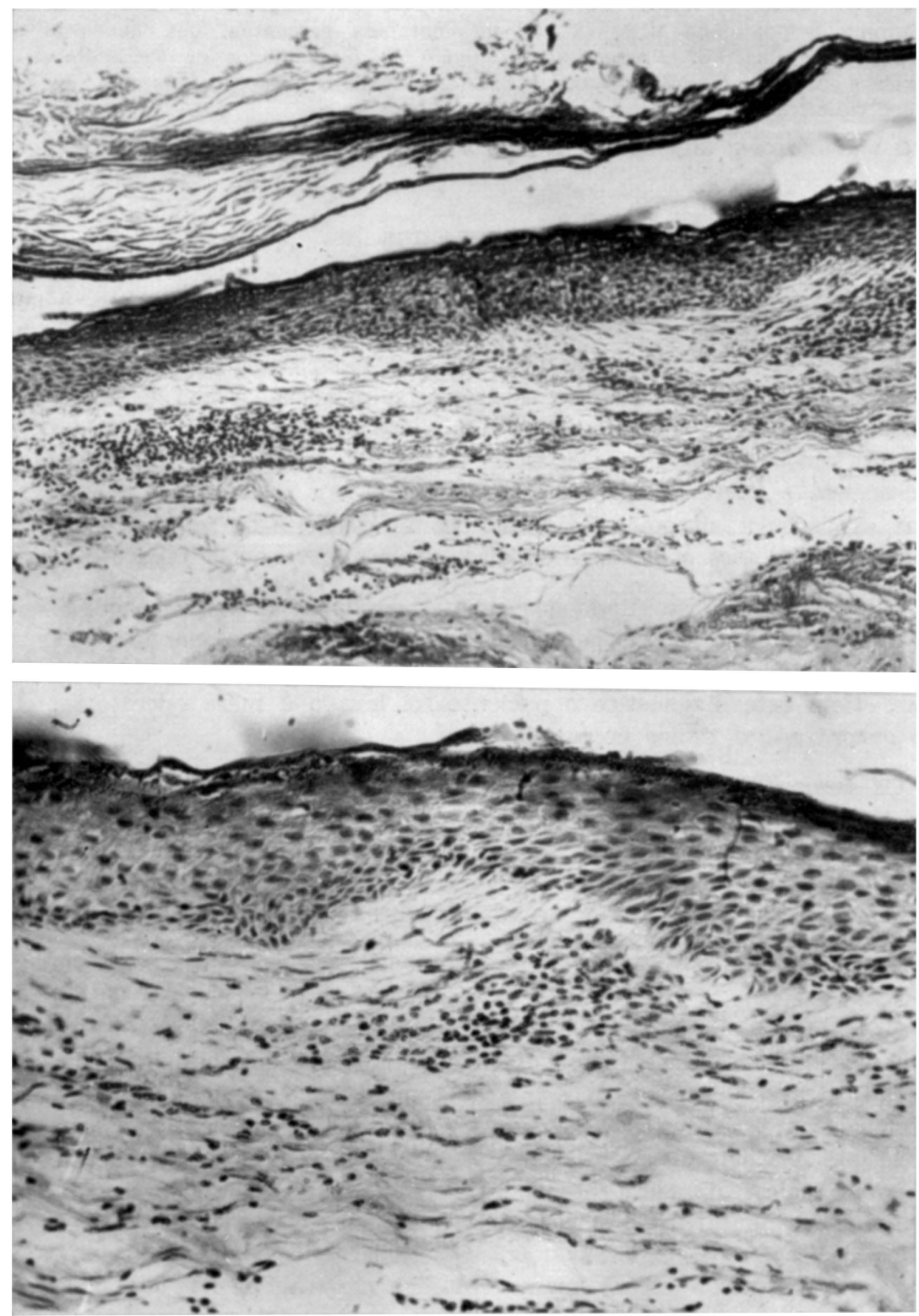

Fig. 1 - Caso G. D. C. Microfotografia do tumor extirpado cirùlgicamente. $\mathrm{Na}$ parte superior, parede do cisto, vendo-se o revestimento interno constituido por epitélio planocelular corneificado, com acentuada descamação córnea; tecido conjuntivo frouxo com infiltrado por linfócitos, constitui o revestimento externo do cisto (col. H. E. 40x). Na parte inferior, o mesmo visto com maior aumento (H. E. $80 x$ ). 
Outros exames feitos durante a internação - Hemograma: leucócitos $8.500 / \mathrm{mm}^{3}$; hemoglobina $12,8 \mathrm{~g}(80 \%)$; na contagem percentual dos leucócitos apenas $1 \%$ de eosinófilos. Exame parasitológico de fezes: ovos de Tricocéfalus trichiurus e Giardia lamblia. Radiografias das coxas e braços: ausência de cisticercose calcificada das partes moles dos membros.

O paciente teve alta em 4-7-1956 sem quáquer distúrbio neurológico.

\section{COMENTARIOS}

A história clínica e o quadro neurológico levaram, inicialmente, à suposição de que o paciente apresentava uma radiculopatia compressiva por hérnia de disco intervertebral, não obstante seja extremamente infrequente esta etiologia em radiculopatias que ocorrem em crianças; Webb e cols. ${ }^{4}$ numa revisão da literatura encontraram 5 casos operados de hérnia de disco intervertebral em pacientes com menos de 15 anos de idade; a história de trauma antecedendo o aparecimento da sintomatologia era referida em 3 casos; em todos os casos a sintomatologia não foi diferente daquela que ocorre nos adultos; em 3 casos o prolapso do disco se localizava no $4^{\circ}$ espaço lombar.

Ultericrmente o resultado dos exames de líquor e sangue conduziram à hipótese de uma etiologia parasitária (cisticercose) imaginando-se que um granuloma cisticercótico se localizasse ao nivel da zona de compressão radicular. Com êste diagnóstico o paciente foi levado à mesa operatória tendo sido encontrado o tumor epidermóide.

Os tumores intra-raqueanos são raros em crianças. A experiência de Ingraham e Matson ${ }^{2}$ registra 63 casos até 1952, quantidade esta que representa aproximadamente uma quinta parte do número de casos (313) de tumores intracranianos dêstes mesmos autores. Dentre os tumores intra-raqueanos os mais freqüentes são os teratomas (12) e cistos dermóides (9) dando, aos chamados "Tumores congênitos", uma incidência relativamente elevada (21/63).

Critchley e Ferguson ${ }^{1}$ reviram a literatura sôbre os epidermóides cérebroespinhais em 1928, mostrando, antes do mais, falta de uniformidade de nomenclatura na designação dêste tipo de tumor pois a denominação de "colesteatoma". com que muitas vêzes são registrados, tem um sentido muito vasto que se presta a defeituosas interpretações. Assim é que são também designados como "colesteatomas", tumores de variada natureza como, por exemplo, os produzidos por otites crônicas, tumores ósseos, cistos de colesterina localizados na região infundibular, etc. Os epidérmoides cérebro-espinhais são tumores de natureza essencialmente epitelial que surgem, não por metaplasia das células da aracnóide, mas sim por inclusão de células embrionárias, como acontece com os dermóides dos quais se destinguem por serem constituidos exclusivamente por elementos de origem ectodérmica, enquanto os dermóides têm elementos de origem endotelial e mesenquimal.

Os epidermóides, tal como os dermóides, não oferecem, em geral, peculiaridades de ordem clínica, dependendo a sintomatologia primordialmente da 
séde do tumor, que pode se localizar nas várias alturas do eixo cérebro-espinhal. Devemos lembrar porém que, tratando-se de malformação ligada a defeito ocorrido no fim do $1^{\circ}$ mês de vida intra-uterina, pode estar associada a alteraçōes cutâneas capazes de sugerir a natureza do tumor. Algumas vêzes o tumor, tal como o dermóide, pode ser associado a espinha bífida, bem como a fístulas que estabeleçam comunicação entre a superfície cutânea e o interior do estojo crânio-raqueano, podendo mesmo servir como porta de entrada para infecções, em geral gravíssimas, de etiologia coli-bacilar, capazes de determinar quadros de meningites ou mielites purulentas; às vêzes estas fístulas abrem-se diretamente na superfície cutânea enquanto que, outras vêzes, abrem-se em planos subcutâneos sendo, portanto, imperceptíveis ao exame. Tem sido salientado o fato de que alguns casos apresentam alterações cutâneas do tipo de umbelicação, de variável dimensão e profundidade, localizada na altura correspondente à do tumor intra-raqueano ou intracraneano, acusando a origem comum dos dois defeitos, ou seja, o momento da separação do neuro-ectoderma do epitélio-ectoderma. Em nosso caso, entretanto, não havia qualquer anormalidade exterior que sugerisse a natureza embrionária do tumo::

Embora não seja nossa intenção rever a literatura sôbre o assunto, devemos assinalar que a literatura brasileira conta com uma publicação de Mattos Pimenta e cols. ${ }^{3}$ em que são registrados dois casos de epidermóides intra-espinhais, mostrando os autores tratar-se de eventualidade clínica bastante rara pois encontraram apenas 26 casos na literatura mundial até a época (1950) da publicação de seu trabalho.

\section{RESUMO}

Caso de tumor epidermóides intra-raqueano, extra-medular ao nivel de $T_{12}$, diagnosticado e tratado cirùrgicamente, em um menino de 9 anos. Os autores chamam a atenção para a dificuldade diagnóstica dêste caso, cujo quadro clínico lembrava o de uma radiculopatia compressiva por hérnia de disco intervertebral. A evolução foi favorável, com recuperação total, sem sequelas. Lembram os autores a necessidade de ser precizada a designação dêsses tumores, que são muitas vêzes confundidos com os cistos dermóides e outros tumores congênitos.

\section{SUMMARY}

\section{Intraspinal epidermoid}

Case report of an intradural, extramedullary epidermoid tumor, at the level of $T_{12}$, in a. 9 year old boy, treated surgically. The authors stress the difficulty to diagnose this case, for the clinical picture seemed that of a radiculopaty due to compression by an intervertebral herniated disc. The evo- 
Iution was favorable, with complete recuperation and without sequelae. The authors point out the necessity of defining the designation of these tumors, often confused with dermoid cysts and other congenital tumors.

\section{BIBLIOGRAFIA}

1. CRITCHLEY, M. D.; FERGUSON, F. R. - The cerebrospinal epidermoids (Cholesteatomata). Brain 51:334, 1928. 2. INGRAHAM, F. D.; MATSON, D. D. - Neurosurgery of Infancy and Childhood. Charles C. Thomas, Springfield (Illinois), 1954. 3. MATTOS PIMENTA, A.; SILVA MARQUES, J.; BARINI, O. Epidermoides medulares. Seára Médica (São Paulo) 5:22, 1950. 4. WEBB, J. H.; SVIEN, H. J.; KENNEDY, R. L. - Protrudent lumbar intervertebral disks in children. J. A. M. A. 154:1153, 1954.

Clinica Neurológica. Hospital das Clínicas da Fac. Med. da Univ. de São Paulo - Caixa Postal 3j61 - São Paulo, Brasil. 